\title{
Fatalities involving illicit drug use in Pretoria, South Africa, for the period 2003 - 2012
} \author{
V Steenkamp, ${ }^{2} \mathrm{PhD}$; G Saayman, ${ }^{1} \mathrm{MB} \mathrm{ChB}$, MMed (Med Forens), FC For Path (SA) \\ ${ }^{1}$ Department of Forensic Medicine, Faculty of Health Sciences, University of Pretoria, South Africa \\ ${ }^{2}$ Department of Pharmacology, Faculty of Health Sciences, University of Pretoria, South Africa
}

J Liebenberg, ${ }^{1}$ BSc Hons; L du Toit-Prinsloo, ${ }^{1}$ MB ChB, Dip For Med (SA) Path, FC For Path (SA), MMed (Path) (Forens);

Corresponding author: $L$ du Toit-Prinsloo (lorraine.dutoit@up.ac.za)

Background. Globally, illicit drugs are responsible for many fatalities annually, yet accurate data on the nature and extent of these deaths in South Africa (SA) are lacking.

Objectives. To investigate the presence and profile of illicit drugs detected in deceased persons who were subjected to medicolegal autopsies and upon whom analyses were carried out in search of illicit drugs in their body fluids at the Pretoria Medico-Legal Laboratory (PMLL), SA, over a 10 -year period.

Methods. A retrospective descriptive case audit was conducted for the period 2003 - 2012.

Results. Screening for illicit drugs was requested in 385 out of 22566 medicolegal autopsies. Results were available for only 281 of these cases, with 154 cases showing the presence of one or more illicit drugs. The demographic profile of positive cases indicated the majority to be male $(90.3 \%)$ and white $(85.1 \%)$. Decedents who tested positive for illicit drugs were predominantly aged between 20 and 30 years (51.9\%). The most frequently detected drug was heroin, the presence of which was confirmed in $35.2 \%$ of cases, followed by cocaine in 19.9\%. Alcohol in combination with an illicit drug or drugs was detected in 56 cases (36.4\%).

Conclusions. Results from this study indicate that illicit drugs were implicated in a considerable number of fatalities in Pretoria. However, it is believed that the figures are a gross under-representation of the actual number of drug users who died during this period. It is therefore recommended that further research be conducted and that drug screening be requested routinely when unnatural deaths are investigated at medicolegal mortuaries, not only to ensure the administration of justice but also to obtain more accurate data for purposes of public health programmes and improve insight into the burden of illicit drug use in SA.

S Afr Med J 2016;106(10):1051-1055. DOI:10.7196/SAMJ.2016.v106i10.11105

Illicit drug use imposes a large burden on societies globally, leading to many deaths each year and a significant number of years of life lost (YLL) due to premature mortality or disabilities. ${ }^{[1]}$ The United Nations Office on Drugs and Crime (UNODC) estimated in its 2012 report $^{[2]}$ that $3.4-6.6 \%$ of the world's population aged between 15 and 64 years had used illegal drugs at least once in the previous year, and in its 2014 report $^{[3]}$ that globally there were 243 million drug users, and that 183000 drug-related deaths had occurred in 2012.

Information on the extent of drug use and drug-related deaths in Africa is extremely limited, as many low-income countries lack the resources and expertise to monitor and assess the problem. ${ }^{[4,5]}$ South Africa (SA) has a population of approximately 54 million and is believed to be the largest trader of illicit drugs in sub-Saharan Africa. ${ }^{[6-8]}$ As a developing country, SA has been undergoing radical social transformation in the last few decades, making it particularly vulnerable to drug abuse, drug trafficking and crime in general. ${ }^{[6,9,10]}$ Other influences predisposing to high levels of drug abuse in SA include widespread poverty, poor education, high unemployment rates, poor border control and political changes or instabilities..$^{[6,7,10-12]}$

Accurate and comprehensive data on the nature and extent of drug use in SA are particularly difficult to obtain owing to the lack of a comprehensive national population study on this problem in recent years. ${ }^{[13]}$ Based on the Central Drug Authority (CDA)'s annual report for $2007 / 08,{ }^{[9]}$ drug abuse statistics for SA indicated that an estimated $8.9 \%$ of the population between the ages of 15 and 64 years used cannabis, $0.4 \%$ opiates, $0.8 \%$ cocaine and $0.9 \%$ amphetamine-type stimulants. ${ }^{[9]}$

Cannabis is the most frequently used illicit drug in SA and is commonly used among all ethnic groups. ${ }^{[3,9,12,14]}$ Heroin is also popular, often sold in low-grade forms mixed with cannabis at a reduced price (i.e. 'nyaope', 'ungah' and/or 'pinch'), making it more accessible to lower socioeconomic groups. ${ }^{[3,5,9,12,14,15]}$ The use of cocaine seems to have decreased slightly since 2008, despite a dramatic increase reported between 1996 and 2006. ${ }^{[5,9,16]}$ The drug of choice varies across SA, with amphetamine-type stimulants such as 'tik' (crystal methamphetamine) being the drug of choice in the Western Cape, while 'CAT' (methcathinone) is more popular in Gauteng. ${ }^{[9]}$ Methaqualone (Mandrax) is also widely used, and although there is some indication that its use has declined in recent years, SA still remains its largest user in the world. ${ }^{[3,17]}$

Drug abusers suffer from a higher mortality and shorter life expectancy compared with other individuals of the same age group in the general population. ${ }^{[18-20]}$ Apart from illicit drugs being the primary cause of death, acquired immunodeficiency syndrome and hepatitis $\mathrm{C}$ contracted from unsafe needle practices, accidental fatalities while intoxicated, unpredictable reactions (to drugs and/ or adulterants) and criminal activity or interpersonal violence also contribute to mortality associated with illicit drug use. ${ }^{[1,6,20,21]}$

In SA it is not standard practice to routinely test samples obtained at autopsy for the presence of substances other than alcohol, such as illicit drugs and/or medicinal substances. The usual/current practice at medicolegal mortuaries in SA is that, at the time of performing the autopsy, the attending medical practitioner/pathologist will (on an ad hoc basis) assess the need to request qualitative and/or quantitative testing for illicit drugs (or other specific substances), based on the autopsy findings and any relevant or suggestive history that may be available at the time (often of a very limited or incomplete nature). This may include suspicious or unexpected deaths for which no overt cause is initially evident, especially among younger persons. The lack of routine 
testing may reflect the historically low rate of illicit use of drug(s)/substance(s) in SA, but is also likely to be a direct consequence of resource constraints, as such testing is labour and cost intensive. Additionally, in respect of analysis of medicolegal samples, there is currently a very large backlog of cases at the state forensic chemistry laboratories. ${ }^{[22]}$ This inability of state toxicology laboratories to adequately service the demands of medicolegal mortuaries (where $>50000$ medicolegal autopsies are being performed annually) may also serve as a disincentive for forensic medical practitioners to routinely collect such samples at autopsy.

Illicit drug use and drug dependence cause considerable harm to individuals and to society and have important implications for the economy, public health and social policy. ${ }^{[4]}$ It is therefore essential to know the extent and monitor the nature and patterns of drug use and dependence in order to detect emerging threats and avoid damaging economic consequences. ${ }^{[23]}$

\section{Objective}

A review of available data shows a paucity of published research in SA that specifically investigated illicit drug use in deceased persons or attempted to correlate such substances with cause or manner of death. The objective of this study was therefore to assess the presence and profile of drugs (in conjunction with demographic characteristics) detected in deceased persons on whom forensic medical autopsies were performed at the Pretoria Medico-Legal Laboratory (PMLL) over the 10-year period 2003 - 2012.

\section{Methods}

The PMLL admits and examines cases of unnatural and unexplained deaths from the greater part of Pretoria (Tshwane metropolitan municipality), the capital city of SA.

A retrospective descriptive study was undertaken by reviewing all case files of deceased individuals on whom postmortem examinations had been conducted at the PMLL from 1 January 2003 to 31 December 2012 , in the course of which biological specimens (blood, urine, vitreous humour, stomach contents, bile, liver or kidney tissue) had been collected and submitted for analysis in respect of illicit/recreational drugs and alcohol. The vast majority of these analyses were performed at the National Department of Health Forensic Chemistry Laboratory (FCL) in Pretoria using standard analytical methods including gas chromatography-mass spectrometry and ultra-performance liquid chromatography-tandem mass spectrometry.

Approval to conduct the study was obtained before commencement from the Research Ethics Committee of the Faculty of Health Sciences, University of Pretoria (ref. no. 143/2014).

\section{Results \\ Cases identified for inclusion in the study}

Over the 10-year study period, autopsies were performed on 22566 bodies, and biological samples from a total of 385 decedents were submitted for illicit drug analysis. Results were available for review at the time of conducting the study for only 281 of these 385 cases $(73.0 \%)$ owing to the backlog of analyses at the FCL. Of the 281 cases analysed, 154 (54.8\%) tested positive for one or more illicit drugs (Table 1).

\section{Demographic information}

The majority of samples submitted for drug analysis $(79.2 \%)$ as well as the majority of cases with positive results $(90.3 \%)$ were from males. Of the 154 decedents with positive results, $85.1 \%$ were white, $11.0 \%$ black and $3.9 \%$ of other ethnicity (coloured, Asian or Indian) (Table 2). In $51.9 \%$ of cases with positive results, the decedent had died between the ages of 20 and 30 years (Fig. 1).

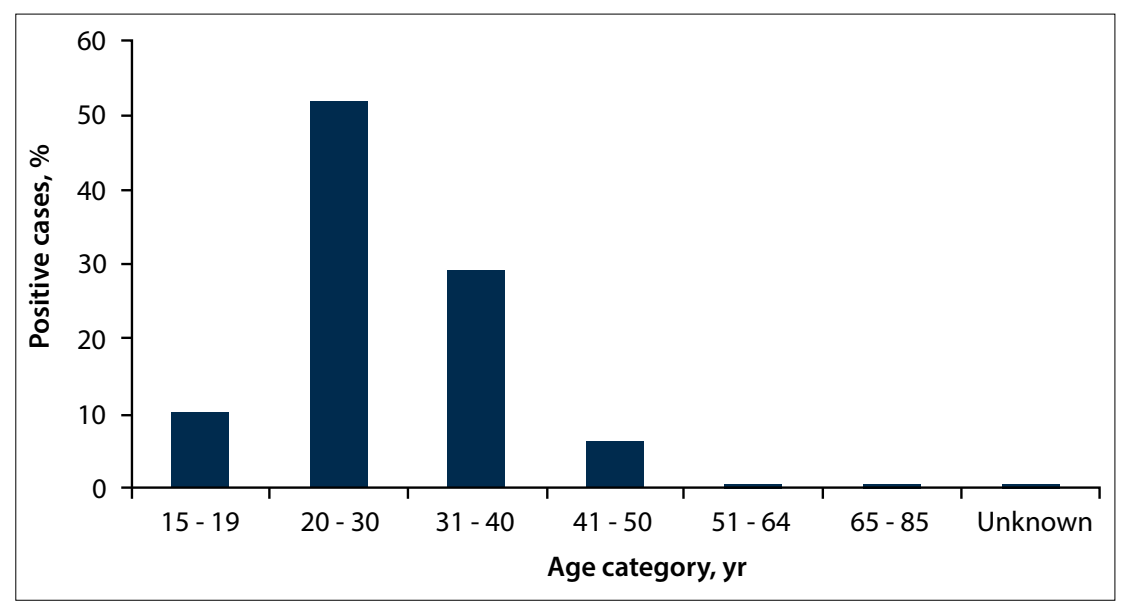

Fig. 1. Age distribution of cases testing positive for an illicit drug $(\mathrm{N}=154)$.

Table 1. Number of cases submitted, analyses done and positive results obtained (per year) in respect of illicit drugs over the 10-year study period $(2003-2012)$

\begin{tabular}{|c|c|c|c|c|c|c|c|c|c|c|c|}
\hline & \multicolumn{10}{|c|}{ Year } & \multirow[b]{2}{*}{ Total } \\
\hline & 1 & 2 & 3 & 4 & 5 & 6 & 7 & 8 & 9 & 10 & \\
\hline Total caseload at PMLL, $N$ & 2266 & 2351 & 2253 & 2364 & 2339 & 2461 & 2341 & 2235 & 2037 & 1919 & 22566 \\
\hline Cases submitted for drug analysis, $n$ & 40 & 27 & 48 & 42 & 41 & 44 & 34 & 37 & 25 & 47 & 385 \\
\hline Cases analysed, $n$ & 39 & 27 & 47 & 40 & 36 & 30 & 16 & 22 & 8 & 16 & 281 \\
\hline Cases with positive results, $n$ & 20 & 18 & 20 & 18 & 20 & 12 & 9 & 16 & 7 & 14 & 154 \\
\hline
\end{tabular}

Table 2. Comparison of demographic data of drug-positive cases with all those sent for analysis

\begin{tabular}{|c|c|c|c|c|c|c|c|c|}
\hline & \multicolumn{4}{|c|}{ Male } & \multicolumn{4}{|c|}{ Female } \\
\hline & White & Black & Other & Total & White & Black & Other & Total \\
\hline Cases submitted for analysis $(N=385), n$ & 205 & 71 & 29 & 305 & 48 & 28 & 4 & 80 \\
\hline Positive cases $(N=154), n$ & 119 & 14 & 6 & 139 & 12 & 3 & 0 & 15 \\
\hline Positive cases, \% & 77.3 & 9.1 & 3.9 & 90.3 & 7.8 & 1.9 & 0 & 9.7 \\
\hline
\end{tabular}




\section{Toxicology results Illicit drugs}

Illicit drugs detected in the decedents included opiates (heroin and morphine), cocaine, amphetamines, methaqualone and cannabis. Heroin was the most common drug detected $(n=99,35.2 \%)$ followed by cocaine $(n=56,19.9 \%)$. Amphetamines and methaqualone were relatively rarely detected, being found in only $18(6.4 \%)$ and $12(4.3 \%)$ cases, respectively. Cannabis was detected in only 13 cases (4.6\%).

No positive results were reported in respect of other drugs of abuse, such as psilocybin, lysergic acid diethylamide (LSD), phencyclidine, gamma-hydroxybutyrate (GHB) or ketamine.

\section{Alcohol}

Testing for alcohol was undertaken in 300 of the 385 study cases. In 56 of the cases that had tested positive for one or more illicit drugs $(n=154)$, the concurrent presence of alcohol was detected, with the average blood alcohol concentration (BAC) being $0.10 \mathrm{~g} / 100 \mathrm{~mL}$.

\section{Autopsy findings}

In 75 of the total of 385 cases there were signs of decomposition at autopsy, suggesting that there had been substantial delays in finding the body or retrieving it from the scene of death. On external examination, 97 cases revealed needle puncture marks and skin track marks possibly associated with intravenous drug use, although it is possible that in some cases the puncture marks may have been due to resuscitation efforts.

\section{Cause of death}

In 109 of the 385 cases (28.3\%), the pathologist concluded that the cause of death was drug related. The causes of death in the remaining 276 cases (i.e. those not specifically ascribed to illicit drugs) included mainly blunt-force injury (motor vehicle accidents, assaults, falling from a height), stab wounds, gunshot wounds, hangings and natural causes. In 96 of the cases a history of previous drug use was noted, and in 81 cases drug paraphernalia were present at the scene of death.

\section{Discussion}

Males (90.3\%) accounted for the vast majority of positive cases, which is in keeping with other studies. ${ }^{[1,23-26]}$ The most common age category for decedents who tested positive for illicit drugs (20 30 years) also correlates relatively well with other studies. ${ }^{[25-27]}$ This reflects a life expectancy approximately 32.9 - 42.9 years lower than that of the general population of SA (62.9 years) $)^{[28]}$ and indicates a significant number of YLL, which places a severe financial and emotional burden on the economy and communities.

The race/ethnic profile of decedents who tested positive for illicit drugs does not reflect the overall racial profile of the population of Tshwane: white decedents accounted for $85.1 \%$ of positive cases, despite only making up $20.1 \%$ of the general Tshwane population, whereas decedents from Tshwane's largest population group, black Africans (75.4\%), only accounted for $11.0 \%$ of positive cases. ${ }^{[29]}$ These results also do not reflect the population profile of decedents admitted to the PMLL, where approximately $76 \%$ of all admissions are black. ${ }^{[30]}$ A variety of factors may account for these findings, including social and cultural norms, socioeconomic factors and the availability of drugs.

Heroin was the most common drug detected in this study, followed by cocaine. These results are consistent with findings from other studies. ${ }^{[24-26,31]}$ It is likely that these drugs are over-represented in samples from decedents, as opiates and cocaine are addictive and carry a greater risk of fatal outcome owing to the risk of central nervous system depression or cardiovascular afflictions, among other complications due to chronic use. ${ }^{[32]}$ Globally, differences exist in patterns of illicit drug use: in Australia, opioids are believed to be responsible for most drug-related deaths, while cocaine has been reported as most commonly detected in drug-related deaths in Florida, USA. ${ }^{[23,33]}$ The low presence of amphetamines and methaqualone in deceased persons may reflect the established knowledge that amphetamine users have lower drug-related mortality risks than opiate users. ${ }^{[34]}$ Interestingly, Stewart et al., ${ }^{[35]}$ using data obtained from the FCL in Johannesburg, reported methaqualone to be the most common drug detected in decedents between 1991 and 1996, with opiates, cocaine and amphetamines only being detected in a very small proportion of cases from the Gauteng area. There therefore appears to have been a substantial change in the type of drug being used in this region over the past two decades.

The low proportion of cases in our study in which cannabis was detected is unexpected, as cannabis has been documented to be the most frequently used drug in Gauteng. ${ }^{[14]}$ However, it is known that cannabis contributes very little to mortality, as reported in the 2010 Global Burden of Disease study ${ }^{[36]}$ and also by Lee et al., ${ }^{[23]}$ who found that cannabis resulted in no deaths among decedents in Florida despite being the third most commonly detected drug. The low incidence of positive cases in our study should nonetheless be investigated further. The possibilities exist that long sample storage periods before analysis may have affected the integrity of samples or the ability to detect the drug, or that metabolite-specific testing had not been carried out. ${ }^{[37]}$

Using two or more illicit substances concurrently increases the likelihood of physical or physiological harm and may more often have a lethal effect. ${ }^{[38,39]}$ Such combined use is usually intended to make the experience more enjoyable or to compensate for a low supply of the primary drug/drug of choice. ${ }^{[40]}$ In 39 cases in our study (13.9\%) the decedent tested positive for more than one illicit drug. The most common combination detected was that of heroin and cocaine, a combination referred to as 'speedballing' among drug users. ${ }^{[41]}$ During speedballing, the two drugs are used simultaneously or following one another, usually intravenously, and the effect produced is a combination of enhanced euphoria and a rush of energy from the cocaine. ${ }^{[41]}$

Besides the individual lethal effects of the various drugs of abuse, drug use in younger persons is a major risk factor for fatal accidents or injuries, whereas in older drug abusers ( $\geq 55$ years) use of drugs may precipitate death due to underlying cardiovascular disease. ${ }^{[20]}$ The high prevalence of suicides, violent behaviour (often resulting in interpersonal violence or conflict with law enforcement officers), drug-induced disease (such as cocaine cardiomyopathy or infectious endocarditis) and unsafe needle practices associated with drug use also contribute to drug-related fatalities. ${ }^{[23,27]}$

Alcohol was detected in combination with one or more illicit drugs in $36.4 \%$ of our study cases, with the highest BAC recorded being an exceptionally high level of $0.47 \mathrm{~g} / 100 \mathrm{~mL}$, present in a victim who also tested positive for cannabis and methaqualone (a combination suggesting the use of what is colloquially referred to as 'white pipe'). The influence of illicit drugs on an individual can be unpredictable and when taken in combination with alcohol, the effect may be exaggerated or harmful, as may be seen when alcohol is consumed with cocaine, leading to the production of cocaethylene. ${ }^{[32]}$

In $\mathrm{SA}$, forensic pathologists/medical practitioners attempt to establish the primary medical cause as well as the mode or mechanism of death, based primarily on autopsy and related findings. No formal finding is made by the forensic medical practitioner as to the manner of death (i.e. homicide, suicide, accident or natural cause). In equivocal cases, inquests are held where the presiding magistrate 
must ultimately make a finding as to the cause and manner of death. The results of toxicological testing cannot be considered in isolation when concluding the cause, mechanism or manner of death, the latter often being a complex decision involving the consideration of a range of factors. Establishing whether the presence of a drug in the body fluids or tissues of a deceased person played a material role in bringing about the death of that person can only be concluded on the basis of thorough assessment of all factors surrounding the case, including the circumstances of death, clinical parameters and actual drug concentrations. It also needs to be considered that in most cases, illicit drugs are produced in clandestine laboratories where no safety or quality control measures exist in the production process. It is common to find that these illicit drugs contain multiple active compounds as well as additives (adulterants and/or 'cutting' agents) that may in themselves be extremely harmful and may cause toxic, allergic or even anaphylactic reactions. ${ }^{[42]}$ It is therefore very important (in the context of both civil and criminal justice administration) for the forensic medical practitioner to have regard for, and access to, relevant information such as death scene findings, medical history, prior use of drugs or medications and consumption of alcohol. ${ }^{[43]}$

Several factors may have impacted negatively on the results of this study. Firstly, the long delay in the analysis of samples could have compromised the accuracy of the results, both qualitatively and quantitatively. Samples are biodegradable and substances therein may be subject to decay or changes over time ${ }^{[4,45]}$ Secondly, the limited information that may be contemporaneously available to the forensic medical practitioner at the time of the autopsy could have led to an under-selection of cases for drug analysis. In addition, the presence of decomposition may significantly lower the chance of detecting drugs as a result of secondary chemical changes or degradation of substances. ${ }^{[46,47]}$ Owing to unavailability of quantitative analysis in many cases (or because long delay periods before sample analysis may preclude reliable quantification), pathologists may be compromised in attributing the death specifically to a drug overdose or interaction.

This study revealed a very low assessment rate, only $1.7 \%$ of decedents being subjected to analysis and illicit/recreational drugs being present in only $0.7 \%$ of the total caseload admitted to the mortuary. This is in stark contrast to the norms and practice that may be expected of an efficient medicolegal investigation-ofdeath service. A review of all forensic autopsy cases conducted at medicolegal centres in Alabama, USA, and Osaka City, Japan, where routine screening had been performed found that drugs of abuse were detected in $33.7 \%$ and $16.2 \%$ of cases, respectively. ${ }^{[48,49]}$

Based on the available epidemiological information and statistics from agencies such as the UNODC, the South African Community Epidemiology Network on Drug Use and the CDA, there is reason to believe that a substantially higher rate of detection of illicit substances is to be expected in victims who undergo medicolegal autopsies in SA. It is clear that very limited inference as to the probable prevalence and use of these substances in decedents examined at medicolegal mortuaries can be drawn from the results of analyses based on such low sample figures. The lower proportion of cases analysed at the FCL from 2006 onwards indicates that the system has become less efficient in recent years. It is likely that over the 10 -year period there were substantially more cases in which illicit drugs were implicated in or had contributed to the death of the individual. It would therefore be beneficial for routine screening to be considered and more studies of this nature to be conducted, preferably in the form of controlled, prospective studies, to better establish the nature and prevalence of illicit drugs in the subset of the population who undergo postmortem examinations, as a possible measure of the use and distribution of such substances in the SA community. This will also provide valuable information on the circumstances surrounding these preventable deaths in order to inform appropriate responses and interventions.

\section{Conclusions}

Results from this study indicate that investigations of fatalities believed to be associated with illicit drug use are a frequent (almost weekly) occurrence at the PMLL. Nonetheless, it is likely that the results obtained from this study are a gross under-representation of the actual number of drug users who have died during the 10-year period as a result of the direct or indirect causes mentioned above. The importance of improving the toxicology situation is two-fold. Firstly, when an unexpected or unnatural death of this nature occurs, the cause/manner of death has far-reaching implications in terms of possible criminal prosecution, insurance payouts and/or closure for grieving family members. Secondly, the role that these drugs (and associated components) play in the cause and/or manner of death should be elucidated in SA, and this will only be possible if consideration is given to future routine drug screening on unnatural deaths at medicolegal mortuaries. This will allow more accurate data to be obtained for the purpose of public health programmes and add insight into the illicit drug use situation in SA. In order to achieve this, the capacity of our national FCLs will need to be substantially improved.

1. Degenhardt L Hall W. Extent of illicit drug use and dependence, and their contribution to the glob burden of disease. Lancet 2012;379(9810):55-70. DOI:10.1016/S0140-6736(11)61138-0

2. United Nations Office on Drugs and Crime. World Drug Report 2012. New York: United Nations, 2012. https://www.unodc.org/documents/data-and-analysis/WDR2012/WDR_2012_web_small.pdf (accessed 9 March 2015)

3. United Nations Office on Drugs and Crime. World Drug Report 2014. New York: United Nations, 2014. http://www.unodc.org/documents/wdr2014/World_Drug_Report_2014_web.pdf (accessed 9 March 2015)

4. Degenhardt L, Bucello C, Calabria B, et al. What data are available on the extent of illicit drug use and dependence globally? Results of four systematic reviews. Drug Alcohol Depend 2011;117(2-3):85-101. DOI:10.1016/j.drugalcdep.2010.11.032

United Nations Office on Drugs and Crime. World Drug Report 2011. New York: United Nations, 2011. http://www.unodc.org/documents/data-and-analysis/WDR2011/World_Drug_Report_2011_ chook. pdf (accessed 9 June 2015 ).

6. United Nations Office on Drugs and Crime. Country Profile on Drugs and Crime - South Africa. Pretoria: Regional Office for Southern Africa, UNODC, 2002. http://www.unodc.org/pdf/southafrica/ Pretoria: Regional Office for Southern Afica, UNODC, 2002.

country_profile_southafrica.pdf (accessed

Thomson K. Overview of the drug abuse problem in South Africa, 2013. http://www.harmonygrou co.za/drugs/overview-of-the-drug-abuse-problem-in-south-africa/ (accessed 10 March 2015).

8. Lehohla PJ. Mid-year Population Estimates 2014 - Statistical Release (P0302). Pretoria: Statistics South Africa, 2014. http://www.statssa.gov.za/publications/P0302/P03022014.pdf (accessed 14 May 2015).

9. Central Drug Authority. Annual Report 2007/08. Pretoria: Department of Social Development, Republic of South Africa, 2008. http://www.dsd.gov.za/cda/index.php?option=com_docman\&task=doc download\&gid=53\&Itemid=116 (accessed 3 June 2015)

10. Morojele N, Parry C, Brook J, Kekwaletswe C. Crime, Violence and Injury Prevention in South Africa - Alcohol and Drug Use. Pretoria: Alcohol and Drug Abuse Research Unit, Medical Research Council, 2012:195-213. http://www.mrc.ac.za/crime/Chapter14.pdf (accessed 13 November 2015).

1. Wannenburg G. Organised Crime in West Africa. African Security Review 2005;14(4):5-16. DOI:10. 1080/10246029.2005.9627583

12. Peltzer K, Ramlagan S, Johnson BD, Phaswana-Mafuya N. Illicit drug use and treatment in South Africa: A review. Subst Use Misuse 2010;45(13):2221-2243. DOI:10.3109/10826084.2010.481594

13. Central Drug Authority. National Drug Masterplan 2013-2017. Department of Social Development, Republic of South Africa, 2013. http://www.dsd.gov.za/index2.php?option=com_docman\&task=doc Republic of South Africa, 2013. http://www.dsd.gov.
view\&gid=414\&Itemid=3 (accessed 13 May 2016).

14. Nel E. Monitoring Alcohol and Drug Abuse Treatment Admissions in South Africa - Data for Gauteng. Phase 33. South African Community Epidemiology Network on Drug Use (SACENDU). Cape Town: Alcohol, Tobacco and Other Drug Research Unit, Medical Research Council, 2013:14-27.

15. Mokwena KE, Huma M. Experiences of 'nyaope' users in three provinces of South Africa. Afr J Phys Health Educ Recr Dance 2014;1(2):352-363.

16. Plüddemann A, Dada S, Parry C, et al. Monitoring Alcohol \& Drug Abuse Trends in South Africa (July 1996 - June 2010). Phase 28. South African Community Epidemiology Network on Drug Use (SACENDU), Research Brief. Cape Town: Alcohol, Tobacco and Other Drug Research Unit, Medical Research Council, 2010:13(2):1-15.

17. Brownfield W. International Narcotics Control Strategy Report. Drug and Chemical Control. Country Reports - South Africa. Washington, DC: United States Department of State, Bureau for International eror

18. Oppenheimer E, Tobult C, Taylor C, Andrew T. Death and survival in a cohort of heroin addicts from London clinics: A 22-year follow-up study. Addiction 1994;89(10):1299-1308. addicts from London clinics: A 22-y

19. Rossow I, Lauritzen G. Balancing on the edge of death: Suicide attempts and life-threatening overdoses among drug addicts. Addiction 1999;94(2):209-219. DOI:10.1046/j.1360-0443.1999.9422095.X

. Stenbacka M, Leifman A, Romelsjö A. Mortality and cause of death among 1705 illicit drug users: A 37 year follow up. Drug Alcohol Rev 2010;29(1):21-27. DOI:10.1111/j.1465-3362.2009.00075.x

21. Fugelstad A, Stenbacka M, Leifman A, Nylander M, Thiblin I. Methadone maintenance treatment: The balance between life-saving treatment and fatal poisonings. Addiction 2007;102(3):406-412. DOI: $10.1111 / j .1360-0443.2006 .01714 . x$

22. James W. Dr Wilmot James calls for inter-ministerial task team to address backlogs at forensic labs [press release on the Internet]. Policy, Law, Economics and Politics, 2015. http://www.politicsweb. 
co.za/politicsweb/view/politicsweb/en/page71654?oid=938320\&sn=Detail\&pid=71616 (accessed 14 January 2016).

23. Lee D, Delcher C, Maldonado-Molina MM, et al. Trends in licit and illicit drug-related deaths in Florida from 2001 to 2012. Forensic Sci Int 2014:245:178-186. DOI:10.1016/j.forsciint.2014.10.024 24. Single E, Robson L, Rehm J, Xie X. Morbidity and mortality attributable to alcohol, tobacco, and illicit drug use in Canada. Am J Public Health 1999;89(3):385-900. DOI:10.2105/ajph.89.3.385

25. Hadidi MS, Ibrahim MI, Abdallat IM, Hadidi KA. Current trends in drug abuse associated fatalities Jordan, 2000-2004. Forensic Sci Int 2009;186(1-3):44-47. DOI:10.1016/j.forsciint.2009.01.012

26. Tuusov J, Vals K, Tonisson M, Riikoja A, Denissov G, Vali M. Fatal poisoning in Estonia 2000-2009: Tren in illegal drug-related deaths. J Forensic Leg Med 2013;20(1):51-56. DOI:10.1016/.j.jlm.2012.04.023

27. Darke S, Degenhardt L, Mattick R. Mortality Amongst Illicit Drug Users: Epidemiology, Causes and Interventions. Cambridge: Cambridge University Press, 2007:20-40.

28. World Health Organization. Global Health Observatory data repository. Life expectancy, data by country (South Africa). Geneva: World Health Organization, 2015. http://apps.who.int/gho/data/ node.main.688?lang=en (accessed 14 January 2016).

29. Census 2011. Metropolitan Municipality 799, City of Tshwane, 2011. http://census2011.adrianfrith. com/place/799 (accessed 2 March 2016)

30. Morris N, du Toit-Prinsloo L, Webber L, Saayman G. The prevalence of HIV in Pretoriass Medico-Legal Laboratory cases, RSA, in 2009. Occup Health South Afr 2014;20(2):6-10.

31. Simonsen KW, Normann PT, Ceder G, et al. Fatal poisoning in drug addicts in the Nordic countries in 2007. Forensic Sci Int 2011;207(1-3):170-176. DOI:10.1016/j.forsciint.2010.10.001

32. Wetli CV. Pathology of drug abuse. In: Karch SB, ed. Drug Abuse Handbook. 2nd ed. Boca Raton, Fla: CRC Press, 2007:72-145.

33. Roxburgh A, Burns L. Drug-induced deaths in Australia. 2007 ed. Sydney: National Drug and Alcohol Research Centre, University of New South Wales, 2011. https://ndarc.med.unsw.edu.au/sites/default/ files/ndarc/resources/NIDIP\%20Bulletin\%20-\%20Drug-induced\%20deaths\%20in\%20Australia\%20 2007.pdf (accessed 13 January 2016).

34. Bartu A, Freeman NC, Gawthorne GS, Codde JP, Holmann CD. Mortality in a cohort of opiate and amphetamine users in Perth, Western Australia. Addiction 2004;99(1):53-60. DOI:10.1111/j.13600443.2004.00602.x

35. Stewart MJ, Moar JJ, Mwesigwa J, Kokot M. Forensic toxicology in urban South Africa. J Toxicol Clin Toxicol 2000;38(4):415-419. DOI:10.1081/clt-100100951

36. Degenhardt L, Ferrari AJ, Calabria B, et al. The global epidemiology and contribution of cannabis use and dependence to the global burden of disease: Results from the GBD 2010 Study. PLoS One 2013;8(10):e76635. DOI:10.1371/journal.pone.0076635
37. Karch SB, Drummer OH. Karch's Pathology of Drug Abuse. 5th ed. Boca Raton, Fla: CRC Press, 2016:824-826.

38. Feigelman W, Gorman BS, Lee JA. Binge drinkers, illicit drug users and polydrug users: An epidemiological study of American collegians. J Alcohol Drug Educ 1998;44(1):47-69.
engelman W, Gorman BS, Lee JA. Binge drinkers, illicit drug users and poly

39. Smith GW, Farrell M, Bunting BP, Houston JE, Shevlin M. Patterns of polydrug use in Great Britain Smith GW, Farrell M, Bunting BP, Houston JE, Shevlin M. Patterns of polydrug use in Great Britain:
Findings from a national household population survey. Drug Alcohol Depend 2011;113(2-3):222-228. DOI:10.1016/j.drugalcdep.2010.08.010

40. European Monitoring Centre for Drugs and Drug Addiction. 2002 Annual Report on the State of the Drugs Problem in the European Union and Norway - Polydrug Use. Lisbon, Portugal: EMCDDA 2002:39-43. http://www.emcdda.europa.eu/html..cfm/index37266EN.html (accessed 19 Augus 2015).

41. Leri F, Bruneau J, Stewart J. Understanding polydrug use: Review of heroin and cocaine co-use. Addiction 2003;98(1):7-22. DOI:10.1046/j.1360-0443.2003.00236.x

42. Bono JP. Criminalistics: Introduction to controlled substances. In: Karch SB, ed. Drug Abuse Handbook. 2nd ed. Boca Raton, Fla: CRC Press, 2007:50.

43. Harding-Pink D, Fryc O. Assessing death by poisoning: Does the medical history help? Med Sci Law 1991;31(1):69-75.

44. Kerrigan, S. Sampling, storage and stability. In: Negrusz A, Cooper G, ed. Clarke’s Analytical Forensic Toxicology. 2nd ed. London, UK: Pharmaceutical Press, 2013:335-356.

45. Dinis-Oliveira RJ, Carvalho F, Duarte JA, et al. Collection of biological samples in forensic toxicology. Toxicol Mech Methods 2010;20(7):363-414. DOI:10.3109/15376516.2010.497976

46. Pounder D, Jones G. Post-mortem drug redistribution - a toxicological nightmare. Forensic Sci In 1990;45(3):253-263. DOI:10.1016/0379-0738(90)90182-x

47. Drummer OH, Gerostamoulos J. Postmortem drug analysis: analytical and toxicological aspects. The Drug Monit 2002;24(2):199-209.

48. Gruszecki AC, Booth J, Davis GG. The predictive value of history and scene investigation for toxicology results in a medical examiner population. Am J Forensic Med Pathol 2007;28(2):103-106. DOI:10.1097/PAF.0b013e318061956d

49. Tominaga $M$, Michiue $T$, Inamori-Kawamoto $O$, et al. Efficacy of drug screening in forensic autopsy: retrospective investigation of routine toxicological findings. Leg Med (Tokyo) 2015;17(3):172-176. DOI:10.1016/j.legalmed.2015.01.001

Accepted 10 June 2016 